\title{
Higher Blood Lead Levels among Childbearing Women in Nearby Addis Ababa-Adama Highway, Ethiopia
}

\author{
Daniel Haile Chercos and Haimanot Gebrehiwot Moges \\ Department of Environmental and Occupational Health and Safety, Institute of Public Health, University of Gondar, \\ P.O. Box 196, Gondar, Ethiopia
}

Correspondence should be addressed to Daniel Haile Chercos; daniel.haile7@gmail.com

Received 15 December 2015; Revised 23 February 2016; Accepted 3 March 2016

Academic Editor: Jennifer L. Freeman

Copyright (C) 2016 D. H. Chercos and H. G. Moges. This is an open access article distributed under the Creative Commons Attribution License, which permits unrestricted use, distribution, and reproduction in any medium, provided the original work is properly cited.

\begin{abstract}
Objective. The aim of this research was to compare blood lead level of childbearing women near Addis Ababa-Adama highway with those who live far from it. Study Design. A comparative cross-sectional study design was used to compare blood lead levels of 40 childbearing women (study group) who lived relatively near Addis Ababa-Adama highway and other 36 childbearing women (comparative group) who lived relatively far $(10 \mathrm{~km})$ from the highway. Methods. In the study, women having a fertile age within 15-49 years were considered as "childbearing women." Blood samples were collected from each group and analyzed for blood lead level comparison. Result. The study indicated significant blood lead level difference $(p<0.001)$ between the groups. The study group had higher blood lead level $(34.32 \pm 6.39 \mu \mathrm{g} / \mathrm{dL})$ than the comparative group $(8.47 \pm 3.01 \mu \mathrm{g} / \mathrm{dL})$. The mean blood lead level of both groups was higher than the advised blood lead concentration for a woman to avoid occupational or vocational lead exposure. Conclusion. This study concluded that blood lead level of women who lived relatively near Addis Ababa-Adama highway was significantly higher than those who lived relatively far from the road.
\end{abstract}

\section{Introduction}

Exposure to environmental lead is clearly a major public health hazard. Due to rapid industrialization and the persistence of lead in the environment, exposure is likely to remain a significant public health problem in most developing countries for the upcoming years [1]. One of the major atmospheric pollutants in urban environment is automobile emissions [2]. High number of vehicles and the patterns usage of those vehicles resulted in the fact that lead is highly abundant in urban environment; researches showed high accumulation of lead in areas near busy highways [3].

There are activities that have been done to phase out leaded gasoline globally, and Ethiopia is one of those countries that phased out the usage of leaded gasoline since June 2003 [4]. However, the problem still exists because lead is not only emitted from leaded gasoline; research done in Denmark indicates that lead can also be emitted significantly from other vehicle activities like brake wares, engine oils, road abrasion, and tyer wears [5]. The problem is still pronounced because most of the vehicles used for transportation activities in Ethiopia are very old, and the research done by the Ethiopian road authority indicated that $65 \%$ of vehicles in Ethiopia use gasoline as a fuel and $35 \%$ of all vehicles in Ethiopia are older than 20 to 23 years. Though the old cars do not use leaded gasoline, low efficiency of the old cars due to the late technology design might bring excess engine oil spillage, excessive break wears, tyer wears, and road abrasion [4].

There are limited researches done in Ethiopia considering lead exposure as a public health problem; most of them were on occupational settings. Lead exposure on women inhabitants near highway was identified as a research gap. Women in their fertile age were chosen as study subjects as they are at risk of developing lead health effects at lower level exposure; if they bear a child, lead can easily affect the children to be born and cause various health problems. Therefore, this study aimed at comparing the blood lead level of childbearing women who were living relatively close and distant from busy roads of Addis Ababa-Adama highway. In the study, women 
having a fertile age within 15-49 years were considered as "childbearing women."

\section{Materials and Methods}

A comparative cross-sectional study was carried out in Addis Ababa-Adama highway on 154 women residing in Ada district, Kebele Denkaka, located $60 \mathrm{~km}$ from Addis Ababa and $12 \mathrm{~km}$ from the district center Bishoftu (former Debre Zeyit). The study was conducted from January 1 to June 1 , 2011. Research activities of the study were commenced upon ethical approval by Jimma University Ethical and Research Committee. Households who resided around both sides of Addis Ababa-Adama highway were 154 in number, out of which 40 childbearing women were selected from the nearest households as a study group using systematic random sampling technique. Another 36 childbearing women were systematically selected at random from a group of 76 households who lived relatively far $(10 \mathrm{~km})$ from the highway and they were considered as a comparative group.

Women who lived near Addis Ababa-Adama highway for at least 3 months were included in the study due to the fact that half-life of lead in human blood is around 36 days [6]. Women working in one or more of workplaces (painters and remodelers, battery manufacturing and recycling, automotive radiator manufacturing and repair, casting and machining lead, brass, bronze, pewter, and white metal plating operations, manufacturing or the use of leaded paints, inks, dyes, glazes, or pigments, lead soldering such as in the electronics industry, salvaging and recycling scrap metal, manufacturing ceramics, manufacturing leaded glass or crystal, manufacturing ammunition and explosives, compounding plastic resins, autobody repair, and making stained glue) were excluded from the study [7]. The study considered blood lead level of women as dependent variable of the study whereas age of woman, housing conditions, type of utensils women use during food preparation, and distance of houses from the highway were taken as independent variables.

Four-milliliter venous blood samples were collected from each study unit using vacutainer tubes containing $7.2 \mathrm{mg}$ $\mathrm{K}_{2}$ EDTA by qualified laboratory professionals. Observation of household environment was inspected using checklist (Annex I) by principal investigator to find out variables like housing condition and type of utensils they use during food preparation and dining to determine if there were other possible sources of lead in the household environment of respondents.

Data quality was assured by using vacutainer tube containing $7.2 \mathrm{mg} \mathrm{K}_{2}$ EDTA (preserving agent), appropriately labeling sample tubes before the collection of samples, using qualified medical laboratory professional as blood sample collector, storing all samples at $4^{\circ} \mathrm{C}$ till the date of digestion, and using standard procedures for the laboratorial analysis. Blood samples analysis was carried out based on the procedure stated by NIOSH, titled as Manual of Analytical Methods (NMAM), Fourth Edition, "Lead in Blood and Urine": Method 8003, issue 2 (1994) [8]. During the analysis step, all analytical procedures were carried out meticulously and high grade reagents and chemicals required for trace

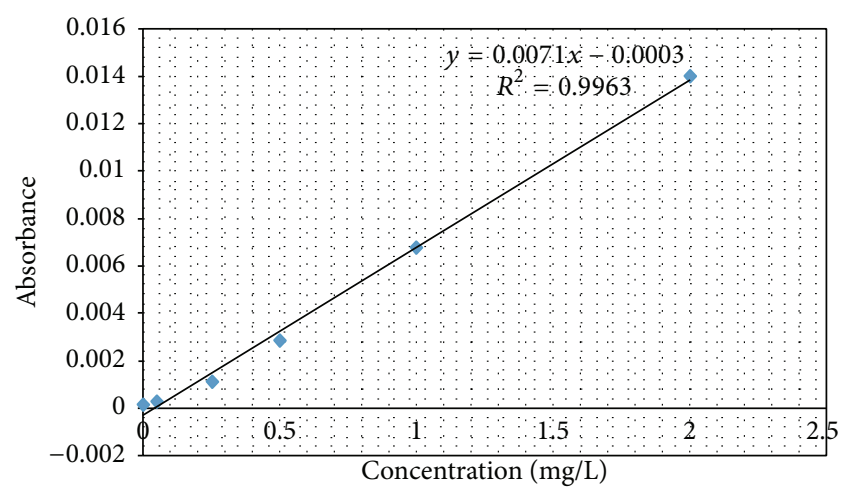

FIgURE 1: Analytical calibration curve for blood lead level analysis.

metal analysis were used so as to calibrate the Atomic Absorption Spectrophotometer (AAS). Calibration curves were constructed and triplication of the analysis was taken as measures of quality assurance (Figure 1).

Data gathered on age, distance of the women residences from highway, household environment inspection, and laboratory blood lead level of women were recorded and processed using Microsoft Excel for Windows XP, 2007, and SPSS for Windows version 16. Pearson and spearman correlations were used to see if there was a correlation between blood lead level with age of women, presence of other sources of lead in the housing environment, and distance of their houses from the highway. Independent sample $t$-test was used to see if there was significant difference in blood lead level between study and comparative groups.

\section{Results and Discussion}

Blood samples were taken from all 76 women and observation was done in each woman. Regarding the occupations of the respondents, the majority $(86.5 \%)$ were housewives, coble stone workers $(1.4 \%)$, daily laborers $(2.7 \%)$, farmers $(2.7 \%)$, students $(5.4 \%)$, and traders $(2.7 \%)$. The mean ages of participants in the study and comparative groups were found to be $27.6 \pm 7.18$ and $26.3 \pm 6.27$, respectively. An independent samples $t$-test was used to compare age between study and comparative groups and there was no significant difference in the age of study group $(\mathrm{M}=27.6, \mathrm{SD}=7.18)$ and comparative group $(\mathrm{M}=26.3, \mathrm{SD}=6.27)$ conditions; $t(74)=1.359, p=$ 0.178 . Spearman correlation indicated that there was no significant correlation between age of respondents and their blood level $(r=0.197, p=0.81)$. This finding is in line with the finding of Gebrie et al. [9] which stated that age and blood lead level were not correlated in the exposed group. The possible reason for this result might be due to the fact that the type of sample taken to assess the lead exposure level in the blood is a way of quantifying recent lead exposure and only stays around 36 days in it after exposure [6]. A good indication of chronic lead exposure might be taking sample from bone and teeth which shows the accumulation of lead in the body.

Bivariate analysis showed that there was no correlation between the blood lead level of respondent and the presence of other sources of lead in the household environment. 


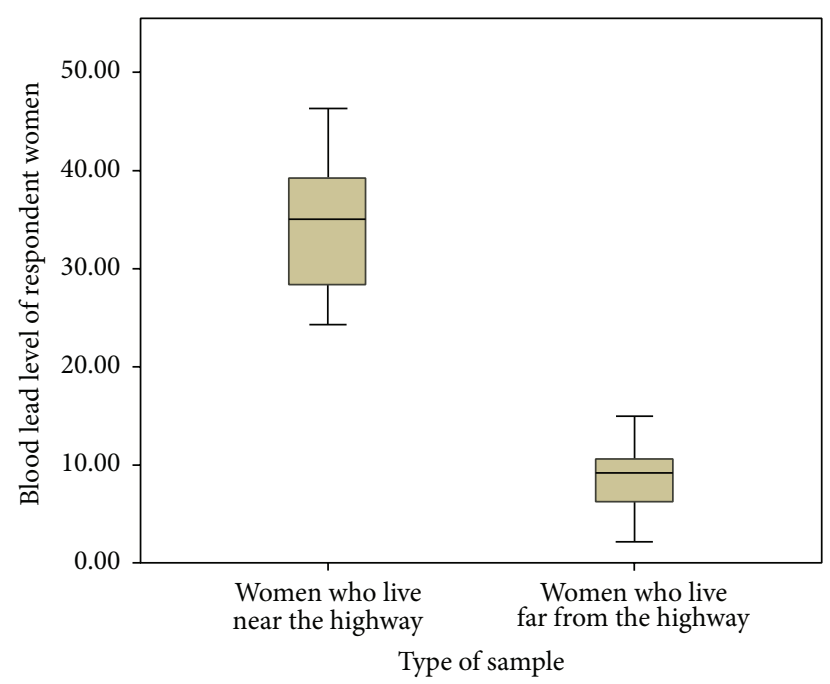

Figure 2: Blood lead level of respondent women around Addis Ababa-Adama road, 2011.

Hence, multivariate analysis was not implemented for further ruling out effect due to confounding factors.

Blood lead levels of study and comparative groups were found to be $34.32 \pm 6.39 \mu \mathrm{g} / \mathrm{dL}$ and $8.47 \pm 3.01 \mu \mathrm{g} / \mathrm{dL}$, respectively. Apparently, the box plot indicated that the study group had more exposure to lead than the comparative group (Figure 2). The analysis of independent sample $t$-test done between the study and comparative groups blood lead level also showed that there was a significant blood lead difference, $t(72)=21.522, p<0.001$.

This distinct difference is attributed to lead exposure from busy road. Scholars conclude that highway environments are highly polluted due to emission from vehicles, and they confirmed that soil, water, and air around busy roads have significantly higher lead content than nonbusy roads [10]. This claim is supported by other researches indicating that vehicular emission is responsible for more than 90 percent of all atmospheric emission and roadside soil lead content [11]. There is also a strong positive and direct relationship between roadside soil lead and traffic density of the road [12]. The relationship of environmental lead concentration and human blood lead level was also studied in United States of America; in the study, daily variation in atmospheric lead was associated with daily variation of lead in soil which give rise to a seasonal variation with known/observed child blood lead level. It hypothesized lead exposure pathway from soil to air dust to the body of a child [13]. In other words, having residence near busy road can be a risk factor for high blood lead level [14].

The findings of this research are in line with similar study done in India that showed women residing in high traffic areas had two times higher blood lead level than women residing far from high traffic areas [15].

The blood lead level findings of this study group are similar to the research done in Egypt on pregnant women suffering from preeclampsia and healthy pregnant ones with blood lead levels $37.68 \pm 9.17 \mu \mathrm{g} / \mathrm{dL}$ and $14.5 \pm 3.18 \mu \mathrm{g} / \mathrm{dL}$ $(p<0.001)$, respectively [16]. The findings of this research were also in accordance with another comparative study of occupational lead exposure from workers in Jimma, Ethiopia, where female workers were found to have higher blood lead level $(42.04 \pm 4.11 \mu \mathrm{g} / \mathrm{dL})$ than environmental lead exposure [9]. On the other hand the findings of this study are different from other research done in Egypt on a woman who experienced repeated abortion having blood lead levels of $19.78 \pm$ 3.85 and $10.53 \pm 1.01$, respectively [17]. The difference may be the fact that the study group of our research had higher environmental lead exposure through the congested road traffic.

The trend of lead exposure of the study was in contradiction with recent researches done in United States of America (USA) suggesting that blood lead level of childbearing women was decreasing in the last decades [18]. Even though measures taken to reduce exposures of lead have resulted in a significant decrease in community blood lead level in the United States and other industrialized countries [19], the reduction of lead was unlikely in emerging countries including Ethiopia [20]. Note also that the mean blood lead level of comparative group $(8.47 \pm 3.01 \mu \mathrm{g} / \mathrm{dL})$ in this study was also higher compared to recent recommended exposure of blood lead level on literature $2 \mu \mathrm{g} / \mathrm{dL}$ [21] for successful prevention of risks related to lead exposure and concentration advised for pregnant women to avoid occupational or vocational lead exposure that would result in blood lead concentrations as $>5 \mu \mathrm{g} / \mathrm{dL}[22,23]$. The reason why the blood lead level of the comparative group was higher might be due to the custom that wives help their husbands in their farms even though they are considered as housewives. Farming was found to be associated with increased blood lead level in men [19]. Lead on husbands' work clothes, equipment, hands, and so forth may also be a source of exposure for their wives [17].

Diesel and gasoline emissions are the primary components of traffic exhaust causing people working or living near high traffic roads to be affected with various health issues, including cancer [24]. Lead level in pregnant women is associated with miscarriages, abortions, and stillbirths. Excessive amount of lead in the body can cause disorder in the metabolism of other microelements such as iron, copper, and zinc which has a negative effect on the function of health and kidney [25]. Since lead easily crosses the placenta and the fetal blood-brain barrier [25], it can irreversibly affect cognitive development [26, 27]. Lead exposure during pregnancy can also cause spontaneous abortions [28], congenital malformations [29], reduced birth weight [30] and length [31], gestational hypertension [32], and impaired neurodevelopment [33].

Despite the fact that meta-analysis review indicated there is no threshold level for lead exposure as any level of exposure could be detrimental $[18,34,35]$, precautions on recommended blood lead level should be in the forefront; for instance, USA recommended that maternal blood lead level should be kept $<5 \mu \mathrm{g} / \mathrm{dL}[36,37]$.

In the study, regression of the distance of households from the highway with blood lead level shows a negative relation$\operatorname{ship}\left(p=0.013, R^{2}=15.5\right)$. As the distance of households from the highway increases, the inhabitant blood lead level decreases which is defined by the regression equation: $Y=$ $-0.117 X+64.88$. Pearson correlation $(r=-0.319, N=76$, 
$p=0.045)$ has been observed describing the relationship between the distance of the house and blood lead level of the respondents. Regression of blood lead level and distance of the households from the highway suggests that, for every increase of 1 meter from the Addis Ababa-Adama highway, there is a decrease of $0.177 \mu \mathrm{g} / \mathrm{dL}$ of blood lead level of respondent women $\left(R^{2}=15.5, N=40 ; p=0.013\right)$. This finding is in line with the idea of negative association between blood lead level and distance from road traffic $[10,38,39]$. This section of the result might be justified because the environmental fate of lead is affected by factors such as the volume of traffic, design of the road way, climate, and surrounding land use. Another justification is the nature of lead which can be described as the least mobile among other heavy metals [40, 41].

\section{Conclusion}

In conclusion, blood lead level of women residing near Addis Ababa-Adama highway was significantly higher than that of women residing far from the road traffic. The mean blood lead level of women of the study was much higher than the advised blood lead concentration for a woman to avoid occupational or vocational lead exposure.

\section{Competing Interests}

The authors declare that they have no competing interests.

\section{Authors' Contributions}

Daniel Haile Chercos was responsible for generating the concept of this research paper, literature review, and organization, the preparation of draft research proposal document, the organization of data collection process, the preparation of draft data analysis and interpretation, the preparation of scientific paper, and the preparation of paper. Haimanot Gebrehiwot Moges participated in the proposal research design process, literature review, data analysis, interpretation process of result, and preparation of the paper.

\section{References}

[1] S. Tong, Y. E. von Schirnding, and T. Prapamontol, "Environmental lead exposure: a public health problem of global dimensions," Bulletin of the World Health Organization, vol. 78, no. 9, pp. 1068-1077, 2000.

[2] S. Azimi, V. Rocher, S. Garnaud, G. Varrault, and D. R. Thevenot, "Decrease of atmospheric deposition of heavy metals in an urban area from 1994 to 2002 (Paris, France)," Chemosphere, vol. 61, no. 5, pp. 645-651, 2005.

[3] D. M. DeMarini, "Genotoxicity biomarkers associated with exposure to traffic and near-road atmospheres: a review," Mutagenesis, vol. 28, no. 5, pp. 485-505, 2013.

[4] P. Bultynck and C. Reliquet, "Phase-out of leaded gasoline in oil importing countries of Sub-Saharan Africa: the case of Ethiopia-action plan," Energy Sector Management Assistance Programme (ESMAP)_Clear Air Initiative Working Paper 13, World Bank, Washington, DC, USA, 2003, Technical Report 038/03, http://documents.worldbank.org/curated/en/2003/12/ 3209031/phase-out-leaded-gasoline-oil-importing-countriessub-saharan-africa-case-ethipia-action-plan.
[5] M. Winther and E. Slentø, Heavy Metal Emissions for Danish Road Transport: National Environmental Research Institute, Aarhus University, Aarhus, Denmark, 2010, http://www.dmu .dk/Pub/FR780.pdf.

[6] A. C. Todd, J. G. Wetmur, J. M. Moline, J. H. Godbold, S. M. Levin, and P. J. Landrigan, "Unraveling the chronic toxicity of lead: an essential priority for environmental health," Environmental Health Perspectives, vol. 104, supplement 1, pp. 141-146, 1996.

[7] M. Rell and J. Galvin, Fact Sheet: Lead Hazard in the Work Place, Connecticut Department of Public Health, 2005.

[8] NIOSH, Lead in Blood And Urine: Method 8003, no. 2, DIANE, 4th edition, 1994.

[9] H. A. Gebrie, D. A. Tessema, and A. Ambelu, "Elevated blood lead levels among unskilled construction workers in Jimma, Ethiopia," Journal of Occupational Medicine and Toxicology, vol. 9, no. 1, article 12, 2014.

[10] H. Ramakrishnaiah and R. K. Somashekar, "Heavy metal contamination in roadside soil and their mobility in relations to $\mathrm{pH}$ and organic carbon," Soil and Sediment Contamination, vol. 11, no. 5, pp. 643-654, 2002.

[11] E. Teju, N. Megersa, B. S. Chandravanshi, and F. Zewge, "Lead accumulation in the roadside soils from heavy density motor way towns of eastern Ethiopia," Bulletin of the Chemical Society of Ethiopia, vol. 28, no. 2, pp. 161-176, 2014.

[12] E. Teju, N. Megersa, B. Chandravanshi, and F. Zewge, "Determination of the levels of lead in the roadside soils of Addis Ababa, Ethiopia," SINET: Ethiopian Journal of Science, vol. 35, no. 2, pp. 81-94, 2013.

[13] S. Zahran, M. A. S. Laidlaw, S. P. McElmurry, G. M. Filippelli, and M. Taylor, "Linking source and effect: resuspended soil lead, air lead, and children's blood lead levels in Detroit, Michigan," Environmental Science and Technology, vol. 47, no. 6, pp. 2839$2845,2013$.

[14] M. H. Rahbar, M. Samms-Vaughan, A. S. Dickerson et al., "Factors associated with blood lead concentrations of children in Jamaica," Journal of Environmental Science and Health Part A, vol. 50, no. 6, pp. 529-539, 2015.

[15] S. Awasthi, R. Awasthi, V. Kumar Pande, R. C. Srivastav, and H. Frumkin, "Blood lead in pregnant women in the urban slums of Lucknow, India," Occupational and Environmental Medicine, vol. 53, no. 12, pp. 836-840, 1996.

[16] S. M. H. Motawei, S. M. Attalla, H. E. Gouda, M. A. El-Harouny, and A. M. El-Mansoury, "Lead level in pregnant women suffering from pre-eclampsia in Dakahlia, Egypt," The International Journal of Occupational and Environmental Medicine, vol. 4, no. 1, pp. 36-44, 2013.

[17] S. M. Attalla, S. A. El-Dakroory, S. M. Mosad, and H. E. Goda, "A comparative study of lead, cadmium, zinc and selenium concentrations in pregnant and aborted women," Mansoura Journal of Forensic Medicine \& Clinical Toxicology, vol. 17, no. 2, pp. 27-41, 2009.

[18] M. L. Miranda, S. E. Edwards, G. K. Swamy, C. J. Paul, and B. Neelon, "Blood lead levels among pregnant women: historical versus contemporaneous exposures," International Journal of Environmental Research and Public Health, vol. 7, no. 4, pp. 1508-1519, 2010.

[19] F. Barbosa Jr., M. Fillion, M. Lemire et al., "Elevated blood lead levels in a riverside population in the Brazilian Amazon," Environmental Research, vol. 109, no. 5, pp. 594-599, 2009.

[20] P. J. Landrigan, "The worldwide problem of lead in petrol," Bulletin of the World Health Organization, vol. 80, no. 10, p. 768, 2002. 
[21] S. G. Gilbert and B. Weiss, "A rationale for lowering the blood lead action level from 10 to $2 \mu \mathrm{g} / \mathrm{dL}$," NeuroToxicology, vol. 27, no. 5, pp. 693-701, 2006.

[22] M. J. Kosnett, R. P. Wedeen, S. J. Rothenberg et al., "Recommendations for medical management of adult lead exposure," Environmental Health Perspectives, vol. 115, no. 3, pp. 463-471, 2006.

[23] G. Ngueta and R. Ndjaboue, "Blood lead concentrations in subSaharan African children below 6 years: systematic review," Tropical Medicine \& International Health, vol. 18, no. 10, pp. 1283-1291, 2013.

[24] D. M. DeMarini, "Genotoxicity biomarkers associated with exposure to traffic and near-road atmospheres: a review," Mutagenesis, vol. 28, no. 5, pp. 485-505, 2013.

[25] B. Opeolu, K. Adebayo, P. Okuneye, and F. Badru, "Physicochemical and microbial assessment of roadside food and water samples in lagos and environs," Journal of Applied Sciences and Environmental Management, vol. 14, no. 1, 2010.

[26] T. Sanders, Y. Liu, V. Buchner, and P. B. Tchounwou, "Neurotoxic effects and biomarkers of lead exposure: a review," Reviews on Environmental Health, vol. 24, no. 1, pp. 15-45, 2009.

[27] M. Roosli, "Non-cancer effects of chemical agents on children's health," Progress in Biophysics and Molecular Biology, vol. 107, no. 3, pp. 315-322, 2011.

[28] V. H. Borja-Aburto, I. Hertz-Picciotto, M. R. Lopez, P. Farias, C. Rios, and J. Blanco, "Blood lead levels measured prospectively and risk of spontaneous abortion," American Journal of Epidemiology, vol. 150, no. 6, pp. 590-597, 1999.

[29] H. L. Needleman, M. Rabinowitz, A. Leviton, S. Linn, and S. Schoenbaum, "The relationship between prenatal exposure to lead and congenital anomalies," The Journal of the American Medical Association, vol. 251, no. 22, pp. 2956-2959, 1984.

[30] D. Bellinger, A. Leviton, H. L. Needleman, C. Waternaux, and M. Rabinowitz, "Low-level lead exposure and infant development in the first year," Neurobehavioral Toxicology and Teratology, vol. 8, no. 2, pp. 151-161, 1986.

[31] M. Hernandez-Avila, K. E. Peterson, T. Gonzalez-Cossio et al., "Effect of maternal bone lead on length and head circumference of newborns and 1-month-old infants," Archives of Environmental Health, vol. 57, no. 5, pp. 482-488, 2002.

[32] D. A. Kennedy, C. Woodland, and G. Koren, "Lead exposure, gestational hypertension and pre-eclampsia: a systematic review of cause and effect," Journal of Obstetrics and Gynaecology, vol. 32, no. 6, pp. 512-517, 2012.

[33] D. C. Bellinger, "Teratogen update: Lead and pregnancy," Birth Defects Research A: Clinical and Molecular Teratology, vol. 73, no. 6, pp. 409-420, 2005.

[34] H. L. Needleman and P. J. Landrigan, "What level of lead in blood is toxic for a child?" American Journal of Public Health, vol. 94, no. 1, pp. 8-9, 2004.

[35] D. J. VanderJagt, S. N. Okolo, L. Romero, M. Millson, and R. H. Glew, "Lead levels in the milk of Fulani women in Nigeria," Journal of the National Medical Association, vol. 93, no. 3, pp. 104-108, 2001.

[36] A. S. Ettinger and A. M. Wengrovitz, Guidelines for the Identification and Management of Lead Exposure in Pregnant and Lactating Women, US Department of Health and Human Services, Centers for Disease Control and Prevention, National Center for Environmental Health/Agency for Toxic Substances and Disease Registry, 2010.

[37] Obstetricians ACo, "Gynecologists. Lead screening during pregnancy and lactation," Committee Opinion 533, 2012.
[38] R. A. Thakre and M. Vittal Rao, "Biomonitoring of auto exhaust pollutants with special reference to lead," in Current Pollution Researches in India, R. K. Trivedy and P. K. Goel, Eds., pp. 5963, New India Publication, New Delhi, India, 1985.

[39] M. Yousefi and M. Ehteshami, "Lead contamination and pollution indexes in roadside soil in Tehran, Iran," Iranian Journal of Health Sciences, vol. 3, no. 4, pp. 8-23, 2015.

[40] M. I. Lone, S. H. Raza, S. Muhammad, M. A. Naeem, and M. Khalid, "Lead content in soil and wheat tissue along roads with different traffic loads in Rawalpindi district," Pakistan Journal of Botany, vol. 38, no. 4, pp. 1035-1042, 2006.

[41] SCU, Science for Environment Policy In-Depth Report: Report Produced for the European Commission DG Environment, 2013, http://ec.europa.eu/science-environment-policy. 

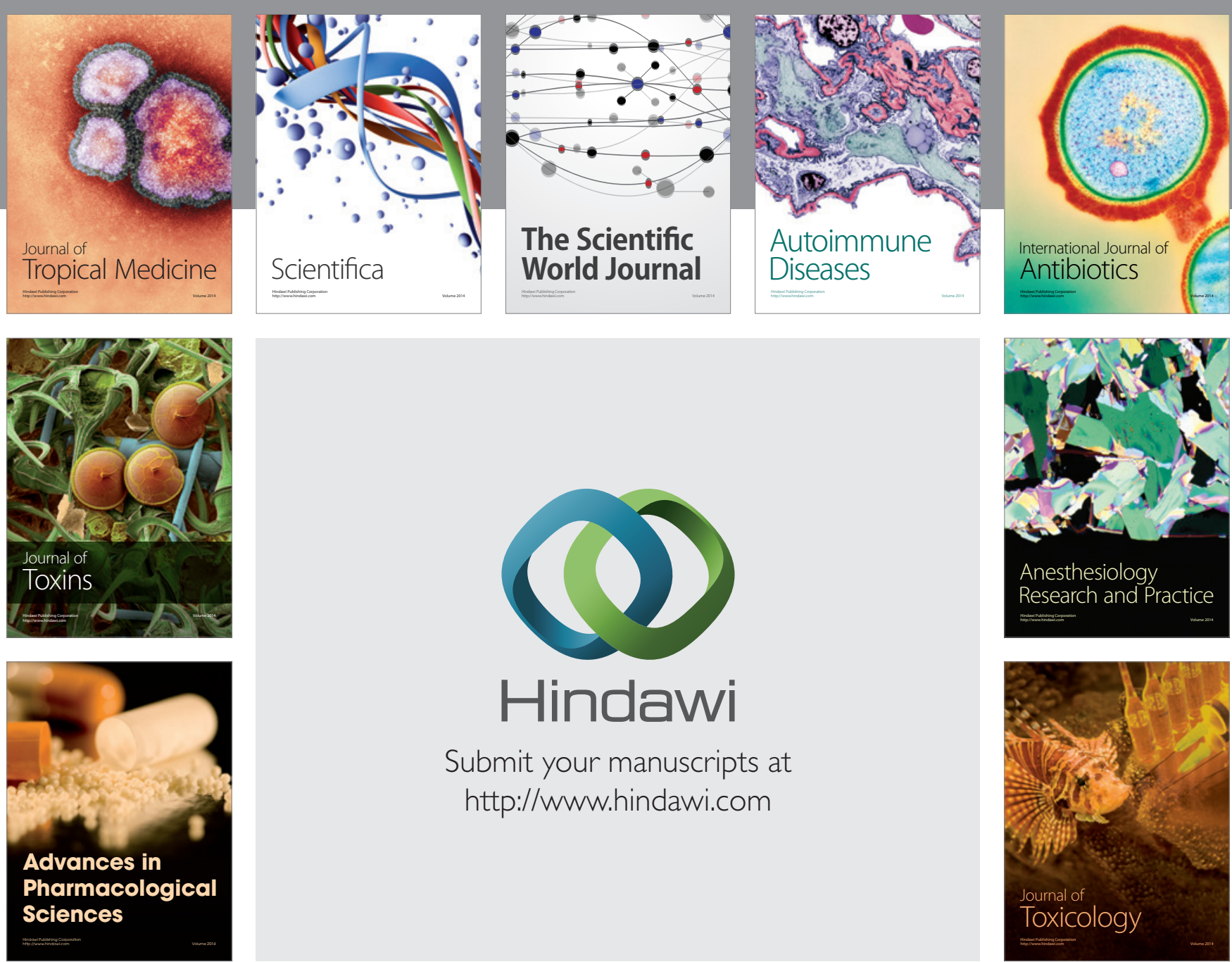

\section{Hindawi}

Submit your manuscripts at

http://www.hindawi.com
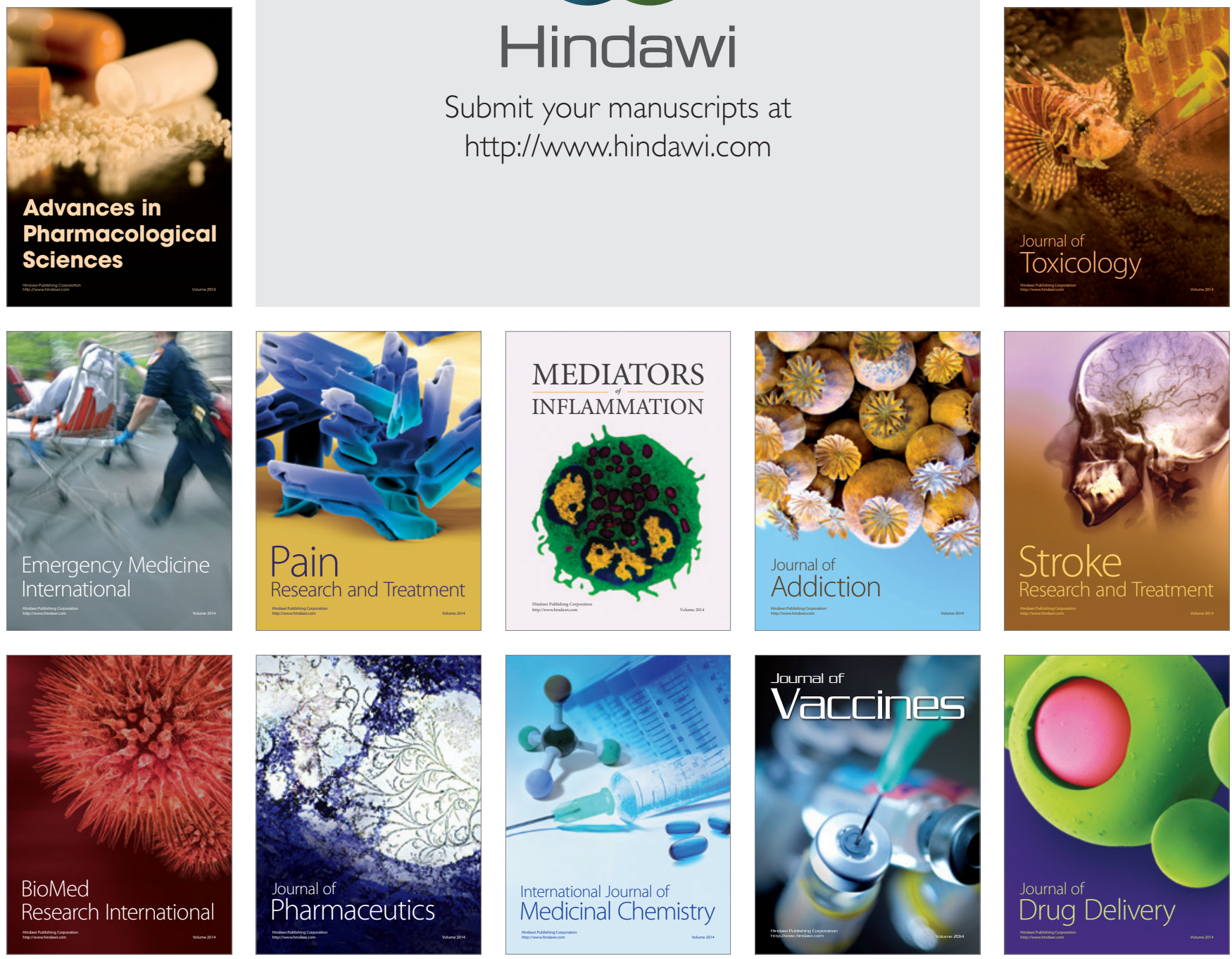